\title{
A LEITURA LITERÁRIA NO ESPAÇO PRISIONAL: UMA EXPERIÊNCIA COM LEITORAS NA PENITENCIÁRIA FEMININA DA CAPITAL (PFC- SP)
}

LITERATURE READING IN THE PRISION ENVIRONMENT: AN EXPERIENCE WITH READERS IN PENITENCIÁRIA FEMININA DA CAPITAL (PFC-SP)

Vima Lia de Rossi Martin ${ }^{1}$ Fernanda Mendes Soares Barreiro ${ }^{2}$

1 Professora de Estudos Comparados de Literaturas em Língua Portuguesa na FFLCH/USP.

2 Mestranda do Programa de Pós-graduação em Estudos Comparados de Literaturas de Língua Portuguesa na FFLCH/USP.

Via Atlântica, Sầo Paulo, n. 39, p. 390-415, set. 2021. doi: 10.11606/va.i39.180818 
Resumo: Este texto traça considerações sobre experiências de leitura literária em situação de cárcere a partir de um projeto de remição de pena através da leitura desenvolvido durante dois anos - 2018 e 2019 - com cerca de cinquenta mulheres internas na Penitenciária Feminina da Capital (PFC) na cidade de São Paulo. Para contextualizar o projeto, apresenta-se inicialmente um breve panorama das políticas de encarceramento no Brasil; na sequência, são delineadas as principais linhas de força das ações desenvolvidas na penitenciária; e, por fim, reflete-se sobre o potencial da leitura literária no favorecimento de processos de humanização e de construção e reconstrução de nossas identidades pessoais e coletivas.

Palavras-chave: Leitura literária, humanização, remição de pena, sistema prisional, encarceramento feminino 
Abstract: This text outlines considerations on literary reading experiences in prison from a remission project through reading developed during two years - 2018 and 2019 - with about fifty women interns in the Women's Penitentiary of the Capital (PFC) in the city from Sao Paulo. To contextualize the project, a brief overview of the incarceration policies in Brazil is initially presented; next, the main lines of force of the actions developed in the penitentiary are outlined; and, finally, it reflects on the potential of literary reading in favoring humanization processes and the construction and reconstruction of our personal and collective identities.

Keywords: literature reading, penalty remission, humanization, prison system, female incarceration 


\section{A interseccionalidade de classe, raça e gênero nas políticas de encarceramento no Brasil}

O Brasil mantém a terceira maior população carcerária do mundo em números brutos, segundo a base de dados World Prision Brief da Universidade de Londres. O Levantamento Nacional de Informações Penitenciárias (InfoPen), realizado no período de julho a dezembro de 2019 , contabilizou 755.274 pessoas privadas de liberdade, sendo que 33\% desse total são presos provisórios, ou seja, ainda não foram julgados. De acordo com este mesmo órgão, o déficit de vagas no sistema prisional brasileiro é de 312.925 , número preocupante que ilustra o problema da superlotação em nossos estabelecimentos prisionais.

O perfil da população prisional brasileira é predominantemente masculino, negro e jovem. 0 estado de São Paulo concentra o maior número de pessoas em situação de encarceramento do Brasil - são 230 mil presos e presas distribuídos em cerca de 170 unidades prisionais. Ou seja, quase um terço da população carcerária do país está em São Paulo.

Quando pensamos em tipificações penais, metade dos crimes totais cometidos no Brasil são contra o patrimônio $(50,96 \%)$. A segunda maior incidência criminal está relacionada a drogas e corresponde a 20,20\% das prisões efetuadas.

Observando o crescente investimento do Estado brasileiro em políticas de encarceramento e a evi- 
dente delineação de grupos sociais para quem essas políticas são em maior rigor aplicadas, a pesquisadora e ativista Juliana Borges publicou em 2019 o livro Encarceramento em massa, no qual observa que o processo de formação do sistema de justiça criminal brasileiro ocorreu em profunda consonância com a hierarquização social e racial originária do período colonial escravocrata. A análise feita pela autora remonta o período entre 1500 e 1822, quando as chamadas Ordenações Filipinas serviam de código penal para a organização social no Brasil e garantiam o direito do senhor de terras à propriedade das pessoas escravizadas. Após a independência e posterior período imperial, a estrutura das leis que se formavam herdou o caráter patrimonialista que buscava salvaguardar as prerrogativas dos grandes proprietários de terras e de pessoas. É nesse momento também que os ideais iluministas já consolidados na esfera política da Europa aportam por aqui, fazendo aflorar conflitos ideológicos que refletiam as incoerências de um império que se pretendia liberal sem prescindir da instituição escravista.

Todo esse processo de disputas políticas e econômicas que antecederam a abolição do trabalho escravo em 1888 foi marcado por polêmicas sobre o modo como o Estado atuava ao criminalizar levantes e revoltas de pessoas escravizadas, sendo muitas vezes criticado por interferir em assuntos considerados privados, ou seja, concernentes à esfera da proprie- 
dade. Diante das novas forças liberais que ganhavam cada vez mais espaço, acirraram-se as posturas de vigilância e punição contra a população escravizada no Brasil.

Após a Lei Áurea de 1888, seguida da proclamação da República em 1889, o sistema de justiça criminal não apresentou nenhuma ruptura com a antiga visão que perpetuava a ideia de inferioridade das populações negras e indígenas, visões essas que buscaram justificar por séculos a escravidão e a violência infligidas contra esses grupos. Agora liberta, e não mais vista legalmente como propriedade, a população negra teve as suas manifestações culturais e as atividades econômicas - exercidas fundamentalmente por mulheres - criminalizadas no código penal de 1890, promulgado dois anos após a abolição da escravidão.

Em 1894, foi lançado o livro As raças humanas $e$ a responsabilidade penal no Brasil, escrito pelo médico eugenista Raimundo Nina Rodrigues, defendendo um tratamento diferenciado na penalização de raças julgadas inferiores - o negro e o índio. Desta forma, a população negra que chegou escravizada no Brasil e sob a condição de propriedade passa a ocupar o lugar social do crime e esboçar o perfil construído em nosso imaginário como sendo o do criminoso.

Posteriormente, o livro foi relançado em 1938 para pressionar a manutenção de elementos e marcadores de diferenciação racial no Código Penal de 1940. Entretanto, nesta época ganhava prestígio o mito da 
democracia racial nas narrativas sobre a formação do povo brasileiro, e a miscigenação, antes estigmatizada, passava agora a ser celebrada. As legislações a partir desta época retiraram os elementos de diferenciação no tratamento penal entre as raças, o que não significa que a hierarquização racial que deu forma ao colonialismo e se refletiu nos regimes políticos posteriores tenha desaparecido das práticas do sistema de justiça criminal existentes nos dias de hoje.

A partir dos anos 1990, intensificou-se uma política de guerra às drogas em nome de uma suposta defesa da segurança pública e ordem social. Esse cenário de intolerância ao tráfico de drogas abriu precedentes para a criminalização e subsequente punição direcionadas principalmente contra a população negra e periférica, visto que esses atos infracionais em sua maioria estão relacionados a uma realidade social de extrema vulnerabilidade e violência.

A recente política brasileira de enfrentamento às drogas não apenas desencadeou o encarceramento massivo da população, como também reforçou práticas de hierarquização racial e social, mantendo políticas de criminalização que têm como alvo os grupos marginalizados da sociedade brasileira. Dados oficiais divulgados pelo InfoPen indicam que, de 2006 a 2014 - um período de 8 anos -, o número de encarcerados aumentou em mais de 200 mil pessoas.

Este mesmo período de 2006 a 2014 também representou um aumento bastante expressivo no encar- 
ceramento de mulheres quando comparado ao de homens. A população feminina nos presídios brasileiros cresceu $567,4 \%$ enquanto a média de crescimento da população carcerária masculina foi de $220 \%$ no mesmo recorte de tempo. Essas informações endossam as reflexões da filósofa norte-americana Angela Davis que, no livro Estarão as prisões obsoletas?, publicado em 2003, discorre sobre a centralidade da questão de gênero para as discussões acerca do sistema carcerário como um todo. Nessa obra, a autora expõe as tendências globais de aumento do encarceramento entre as mulheres decorrente do complexo industrial-prisional movido pela busca sem precedentes de lucros.

0 termo complexo industrial-prisional foi concebido para contestar a ideia de que o aumento dos índices de criminalidade é a principal razão para explicar o alarmante crescimento da população carcerária. $\mathrm{Na}$ realidade, esse crescimento estaria relacionado a motivações racistas aliadas a um sistema capitalista que sentencia excedentes humanos ao ostracismo social e lucra com a construção e gerenciamento de complexas redes de prisões.

No caso brasileiro, o encarceramento massivo e seletivo da população ganhou respaldo com a Lei de Drogas no 11.343/06, que substituiu a anterior de 1976 e trouxe mudanças que enrijeceram a punição ao tráfico, sem, no entanto, preocupar-se em estabelecer distinções significativas entre usuários e traficantes. Segundo a Iniciativa Negra por uma Nova Po- 
lítica sobre Drogas (INNPD), a lei não apresenta uma visão totalizante sobre o tráfico de drogas ou visa embasar estratégias para desmantelar sua economia; ao contrário, acaba abrindo precedentes para a militarização de territórios periféricos, atingindo implacavelmente quem pratica atos infracionais decursivos de uma realidade de vulnerabilidade social, desestruturação familiar, necessidade de sustento dos filhos e da família, violência e abuso doméstico e público.

Nesse contexto, as mulheres representam o principal alvo das atuais políticas de encarceramento desencadeadas pela guerra às drogas. Segundo o levantamento de dados do InfoPen de julho de 2017, o tráfico de drogas é responsável por 59,58\% das prisões femininas ocorridas no Brasil. Em geral, as mulheres que entram no sistema prisional são jovens, negras, solteiras, possuem filhos, têm baixo nível de escolaridade e renda familiar precária. Antes do encarceramento, não possuíam estabilidade financeira e desempenhavam ocupações de baixa qualificação ou se encontravam desempregadas. Outros estigmas que este grupo social traz consigo são um histórico recorrente de violência doméstica, núcleos familiares instáveis e acesso precário à educação.

A prisão para a população feminina muitas vezes representa uma ruptura ainda mais brusca com a liberdade e com o convívio familiar, pois as mulheres são mais frequentemente abandonadas pelos companheiros e parentes quando comparadas às suas con- 
trapartes masculinas. Embora o número de mulheres encarceradas (cerca de 37.828) seja bastante inferior ao número de homens (aproximadamente 717.446) na mesma situação, é sobre elas que recai a opressão de gênero tramada e refletida nas relações entre sociedade e cárcere. Essa opressão é vivenciada tanto nas imensas filas em dias de visitas nos presídios masculinos - filas estas constituídas majoritariamente por mulheres, que são atravessadas pela realidade do encarceramento na forma de revista vexatória e tratamento humilhante como punição por seus vínculos com os presos, como nas formas de criminalização e penalização empreendidas pelo Estado que insiste em um projeto de manutenção de desigualdades sociais baseado em hierarquias raciais em interseccionalidade com as condições de gênero.

\section{A remição de pena por leitura na Penitenciária Feminina da Capital}

A primeira legislação sobre remição de pena no Brasil é de 1984, ano em que foi promulgada a Lei de Execução Penal (LEP), que estabeleceu a possibilidade de remição de pena através do trabalho. Em 2011, vinte e sete anos depois da promulgação da LEP, essa possibilidade se amplia com o estabelecimento de que o estudo também pode ser considerado fator para a remição das penas. Em 2013 uma nova recomendação do Conselho Nacional de Justiça (CNJ) 
passou a contemplar a prática da leitura - na condição de atividade educacional complementar - também como fator para diminuir o tempo da condenação de pessoas julgadas. Segundo essa última normativa, as pessoas em privação de liberdade têm o prazo de 22 a 30 dias para a leitura de uma obra de literatura, apresentando ao final do período uma resenha a respeito do livro, que deverá ser avaliada - aprovada ou reprovada - pela comissão organizadora do projeto. Cada obra lida possibilita a remição de quatro dias da pena, com o limite de doze obras por ano, ou seja, no máximo 48 dias de remição de pena por leitura a cada doze meses.

É importante destacar que essas três garantias legais - a remição de pena por trabalho, por estudo e por leitura - não se efetivam de maneira igualitária no sistema prisional brasileiro. Seja porque nem todos os presídios garantem esses direitos, seja porque, no interior de cada unidade em que esses direitos são garantidos, o acesso a eles se dá de forma muito parcial e particularizada, pois não há universalidade e nem critérios claros para o acesso às possibilidades de trabalho, estudo ou leitura. Desse modo, o que se observa, na prática, é que o direito das presas e dos presos brasileiros acaba se constituindo como um enorme privilégio - como, vale dizer, são privilégios muitos dos direitos constitucionais fora dos presídios também. 
0 projeto intitulado Travessia foi pioneiro na promoção da remição de pena através da leitura na Penitenciária Feminina da Capital (PFC). Essa penitenciária é uma unidade de regime fechado que fica no bairro do Carandiru, na zona norte da cidade de São Paulo, e agrega cerca de 500 mulheres, tendo a especificidade de concentrar quase toda a população feminina estrangeira que está aguardando julgamento ou cumprindo pena no estado - na PFC há mulheres de mais de 30 nacionalidades diferentes. Considerada uma prisão modelo pelo governo paulista, a PFC é relativamente bem organizada, possui uma escola e oferece vagas de trabalho em três empresas localizadas em seu interior. Também abre espaço para a realização de diferentes projetos e atividades culturais, como aulas de dança e de canto, ainda que para uma porção minoritária das mulheres.

Os integrantes do projeto Travessia, todos vinculados à Universidade de São Paulo, organizaram rodas de leitura com mulheres privadas de liberdade no período de março de 2018 até dezembro de 2019. A relação entre a USP e a PFC se deu através de um acordo de cooperação técnica e estabeleceu que o grupo, coordenado por uma docente do curso de Letras, ficaria responsável pelo desenvolvimento de oficinas de leitura e escrita, bem como pela avaliação e conseguinte aprovação ou reprovação das resenhas elaboradas pelas participantes, antes de esses textos 
serem encaminhados para as respectivas varas criminais.

Ao longo de dois anos, o grupo de mediadores, que contava com cerca de oito pessoas, trabalhou semanalmente no presídio. A participação foi voluntária e se deu principalmente ao longo dos semestres letivos. Nesse tempo, foi realizada a leitura de mais de quinze livros diferentes com um grupo de leitoras composto, em média, por 30 mulheres. Esse grupo era relativamente variável: enquanto algumas leitoras participaram apenas de alguns encontros, outras estiveram presentes por longos períodos, o que permitiu a formação de vínculos significativos. As rodas de leitura eram realizadas no pavilhão da escola, composto por três salas de aula equipadas com lousa e carteiras escolares, uma pequena biblioteca com livros de diversos gêneros e idiomas, buscando contemplar a demanda de presas estrangeiras, e um anexo apelidado de "Templo do Salominho", construído com recursos de uma congregação evangélica a fim de abrigar cultos religiosos e outros eventos.

A escolha dos livros para a leitura coletiva foi marcada por um limite bastante objetivo: a disponibilidade de exemplares. Foram feitas campanhas para a arrecadação de alguns títulos e, inclusive, foram distribuídos textos fotocopiados. Foram lidas obras de Marina Colasanti, Mia Couto, Geni Guimarães, Ariano Suassuna, Clarice Lispector, Graciliano Ramos, Jorge Amado, Geovani Martins, Edgar Allan Poe, Conceição 
Evaristo, Dinha, Rigoberta Menchú entre outros. Ou seja, foi proposta tanto a leitura de textos clássicos ou canônicos - como também de textos contemporâneos e de circulação mais restrita.

0 trabalho de mediação se deu principalmente a partir da realização de rodas de conversa, nas quais cada leitora podia expressar, espontaneamente, suas impressões sobre o texto lido. As intervenções do grupo de mediadores buscavam, via de regra, valorizar as leituras autorais e esclarecer ou ilustrar aspectos textuais e contextuais. E também eram oferecidas orientações formais para a elaboração das resenhas literárias, escritas e reescritas pelas leitoras a fim de garantir uma aprovação formal, necessária antes do encaminhamento ao juiz ou à juíza da vara de execução penal de cada participante do projeto.

A mediação das leituras orientou-se principalmente por reflexões sobre a formação de leitores desenvolvidas por Antonio Candido, bell hooks e Michèle Petit. Candido, que faz a defesa irrestrita da literatura como um direito humano, aposta em seu potencial humanizador, uma vez que a leitura promoveria uma reflexão sobre os valores éticos e forneceria a possibilidade de se viver os problemas cotidianos de maneira dialética. bell hooks ensina sobre a importância da criação de comunidades de leitura, que são espaços de diálogo em que cada participante se sente capaz de compartilhar, num clima de confiança, de afeto e de profundo respeito pela diferença, suas opiniões, 
dúvidas, incertezas e emoções. E Michèle Petit afirma, a partir de sua experiência com pessoas em situação de vulnerabilidade social e psíquica, que a leitura literária possui grande capacidade de favorecer tanto a construção de pontes entre os sujeitos e o mundo, como também entre os sujeitos e suas próprias subjetividades. Nesse sentido, a leitura literária ajudaria a dar sentido à vida e a resistir às adversidades.

Essas ideias estiveram o tempo todo no horizonte de atuação do grupo de mediadores e possibilitaram o estabelecimento de três princípios estruturantes para a mediação das leituras realizadas no ambiente prisional: a defesa do acesso à leitura da literatura (e também à escrita) como um direito de todas as pessoas, a defesa da bibliodiversidade como princípio para a escolha de textos para serem lidos e resenhados pelas leitoras, e a aposta na construção de uma comunidade de leitura como possibilidade de constituição e de reconstituição identitária e de formação de vínculos entre cada leitora e seu universo íntimo e entre as leitoras e a realidade exterior.

\section{Mediação sensível e socialmente implicada}

Os princípios de trabalho do grupo responsável pelo projeto Travessia, essenciais para a realização de uma mediação sensível e socialmente implicada, foram apenas um ponto de partida e, ao longo do projeto, frequentemente surgiram obstáculos e desafios. 
De modo geral, obstáculos relacionados ao contato com a burocracia da instituição e desafios relacionados ao convívio semanal, sempre tão intenso, com as leitoras. Esse contato e esse convívio exigiram muita dedicação e criatividade do grupo de mediadores, com a reformulação contínua de objetivos e a reinvenção de perspectivas e práticas.

Afinal, como garantir o direito à leitura e à escrita - e à consequente remição de pena - para um coletivo de 30 mulheres, com origens, perfis e histórias muito diferentes, submetidas a um regime de controle e vigilância e em condições precárias e adversas?

0 grupo de leitoras era bastante heterogêneo. Elas tinham idades muito variadas, de 18 a mais de 60 anos; possuíam diferentes pertencimentos étnicos e repertórios linguísticos e culturais variados - no grupo, além de mulheres de diversas regiões brasileiras, havia africanas oriundas de países de língua portuguesa, portuguesas e hispano-americanas. Essas mulheres também tinham experiências de escolaridade bastante distintas (havia o caso de uma leitora alfabetizada há pouco tempo, já na penitenciária, e outras que possuíam ensino superior). E, atravessando toda essa diversidade, o que as aproximava era sobretudo a vontade de aprender e a abertura para o estabelecimento de trocas afetivas.

Nos encontros, de cerca de duas horas, muitas mulheres chegavam atrasadas ou se ausentavam pelas mais diferentes razões. Algumas tinham dificuldade 
em deixar a linha de produção onde estavam trabalhando - o regime a que estavam submetidas era bastante opressor e parecia não se alinhar às leis trabalhistas que garantem condições mínimas de trabalho, outras estavam doentes, tinham ido a alguma audiência com o juiz, ou mesmo estavam em isolamento, cumprindo castigo. Relatos de depressão também eram frequentes.

Constantemente, as leitoras estavam cansadas, se queixando de dores físicas, de maus tratos, desanimadas e, ao mesmo tempo, potencialmente cheias de vida e de vontade de se expressar. Precisavam conversar, precisavam falar e ser ouvidas, precisavam contar as suas próprias histórias para sobreviver ao dia a dia do encarceramento.

E como são bonitos os seus modos de narrar! Muito mais do que as próprias histórias, que quase sempre são histórias de abandono, de miséria e de violência, principalmente de violência sexual e doméstica, o modo como as mulheres são capazes de se apropriar e de ressignificar as próprias experiências é admirável. A confiança e a solidariedade que se instauravam nos gestos de fala e de escuta contrapunham-se à carência material e simbólica presente no cárcere. E o grupo de mediadores, à medida que escutava e se deixava afetar pelas histórias narradas, ia se tornando testemunha de diferentes memórias e, de certo modo, atenuando sentimentos de desamparo. 
A par dos relatos das narrativas de vida, elaborados e reelaborados a cada encontro, foi possível também acompanhar as apropriações e reflexões que as leitoras construíram a partir da leitura dos textos propostos. Nas rodas de conversa sobre os livros e na elaboração das resenhas, foi por meio da literatura que os integrantes do projeto Travessia e as leitoras da PFC estabeleceram pontes de comunicação e expressão. Por intermédio de personagens, narradores, versos, espaços e tempos ficcionais e poéticos foi possível tecer uma rede alicerçada no poder do reconhecimento e da arte literária. A literatura se constituiu, portanto, como matéria primordial que alimentou a presença do grupo de mediadores no espaço carcerário e provocou movimentos de emancipação para mulheres em situação de privação de liberdade.

\section{Os processos de escrita de resenhas}

Testemunhar processos de produção escrita no ambiente prisional se mostrou uma experiência reveladora sobre a complexidade do existir dentro do sistema carcerário brasileiro. A leitura e a escrita são processos complementares que permitem aos sujeitos dialogar e interagir com uma comunidade discursiva diversa, apropriando-se de uma linguagem para, então, articular suas próprias intenções e manifestar-se também como autores. 
As leitoras que escreveram resenhas literárias são mulheres subjugadas em suas capacidades, minoradas em suas experiências e subjetividades, categorizadas em estereótipos por um sistema que julga, encarcera, oprime e invisibiliza histórias de dor e injustiça social. Neste contexto, a formação de rodas de leitura e o posterior exercício da escrita, ambas as atividades mediadas pelos princípios de escuta e valorização dos repertórios afetivos e culturais das participantes, permitiu às várias mulheres do grupo encontrar uma voz própria em meio à partilha de ideias e emoções.

Para a escrita da resenha, etapa necessária para garantir a formalização da remição de pena por leitura, foi proposta às leitoras uma estrutura textual simples. A resenha deveria apresentar no primeiro parágrafo informações gerais sobre o livro lido: o autor ou a autora, o ano de publicação, a editora e, caso fosse pertinente à análise que seria feita da obra, algum dado do contexto histórico ou social no qual o escritor ou a escritora e sua obra estavam inseridos. Após essa breve apresentação, um ou dois parágrafos deveriam ser reservados para o resumo sucinto do enredo: quem eram as personagens principais, onde e quando os acontecimentos se deram e quais as principais ações desenvolvidas. Na sequência, um ou dois parágrafos poderiam apresentar uma consideração pessoal sobre o aspecto da obra que mais teria chamado a atenção. Para a conclusão da resenha, as lei- 
toras desenvolveriam livremente as perguntas: "Você indicaria a leitura desse livro? Por quê?". Quando a obra lida e discutida era de poesia ou teatro (Onde escondemos o ouro, de Dinha, ou Auto da compadecida, de Ariano Suassuna, por exemplo), a síntese do livro deveria contemplar temas recorrentes, especificidades no uso da linguagem e criação de imagens - especialmente no caso da poesia - ou aspectos relativos às rubricas ou à ação dramática, no caso do texto teatral.

Cabe ressaltar que o espaço aberto para a exposição de algum pensamento mais pessoal e crítico acerca do que foi lido e discutido coletivamente nas rodas de mediação e compartilhamento de leitura guarda as manifestações mais significativas da produção escrita dessas mulheres. São nessas linhas que se materializam de forma mais evidente o exercício da reflexão, interpretação e apropriação do texto literário, expondo, portanto, o potencial da literatura de favorecer processos de simbolização e ressignificação de trajetórias pessoais e de identidades.

Para ilustrar a potência das resenhas escritas pelas leitoras da PFC, que começaram tímidas e vacilantes no início do processo, mas foram ganhando firmeza e consistência, registramos aqui dois fragmentos de textos produzidos por elas. 0 primeiro foi escrito por G. a partir da leitura do romance Capitães da Areia. No trecho selecionado, a leitora reconhece a atualidade da narrativa de Jorge Amado e tece uma crítica 
indignada à maneira desumana com que são tratadas as crianças e jovens do nosso país:

O livro [Capitães da areia] foi escrito em 1937, entretanto o problema com crianças de rua, desigualdade social, descaso por parte do poder público, vício, a incompetência do sistema no resgate dessas vidas, não apresentou quase nenhum progresso até os dias de hoje.

Até pouco tempo atrás me lembro de ter visto algumas reportagens de maus tratos nas "Fundações C a s a", daí fica a pergunta: é desta maneira que um jovem se recupera? Ou será que estes meninos saem a in d a mais revoltados? Assim ocorreu com Pedro Bala, com Sem Pernas, com Volta Seca e com tantos outros que tiveram a infelicidade de passar por um lugar desses.

G. se valeu do discurso de um escritor canônico para dar voz à própria opinião sobre a sistemática violação de direitos que caracteriza as instituições que executam medidas socioeducativas (as Fundações Casa) e, por extensão, medidas punitivas (as prisões). Na PFC, por exemplo, são comuns os relatos de revistas nas celas que ocorrem de maneira brutal e arbitrária, com a destruição e também com o confisco de objetos pessoais. Aparelhos de rádio e de televisão e até cadernos, lápis e livros eventualmente são apreendidos com truculência, sem razão ou explicação, por agentes penitenciários. É importante levar em consideração que as mulheres privadas de liberdade encontram-se num espaço de opressão, estando condicionadas a julgamentos constantes de 
sua conduta. Portanto, pensar criticamente o sistema prisional, expondo os maus tratos praticados como supostas medidas de reeducação ou reintegração direcionadas a jovens infratores, num documento oficial que será encaminhado ao juiz responsável por seu processo penal com a finalidade de se alcançar a remição de quatro dias de pena, ganha uma dimensão simbólica de resistência frente a realidade de violência estrutural que caracteriza as instituições prisionais.

Outra resenha, escrita por V. a partir da leitura de o diário de Anne Frank, diz assim:

Anne era uma menina quando foi para o "anexo secreto" e, em seu diário, lê-se e sente-se seu amadurecimento e as mudanças sofridas na transição de criança para adolescência. 0 diário começa com um pensamento juvenil e aos poucos seu amadurecimento é nítido, os conflitos com a mãe, aproximação com o pai, o primeiro amor, a consciência que ela tem em relação à vida, ao mundo, num período em que só havia caos. O livro me levou exatamente ao lugar de Anne, me senti a própria, não comparando-se a idade, e sim o momento o qual estou passando. De alguma forma ela estava presa, mesmo com a família, o que não é meu caso, pois aqui estou sozinha. Mas também havia estranhos no anexo, e eles não podiam sair do esconderijo, assim como eu não posso sair daqui no momento que quero. A diferença entre a Anne e eu é que por mais que ela tivesse essa esperança viva que tenho de um dia melhor, eles foram delatados, presos em campos de concentração e Anne morreu de tifo. Eu sei que sairei daqui viva, com amadurecimento e lição de vida e sei que voltarei para minha linda e amada família, e recomeçarei uma etapa de vida. 
Recomendo muito esse livro independente de qualquer situação, pois todos temos momentos escondidos, momentos presos sejam dentro de nós ou de uma rotina. Lendo o relato de Anne Frank dá pra ver que a vida pode ser diferente.

Chama a atenção o modo como V. pensa a própria vida a partir das aproximações que vai estabelecendo com a realidade de perseguição e confinamento vivida por Anne Frank. Sua identificação com a personagem a leva a assumir o que poderíamos compreender como uma "posição de sujeito", permitindo-se imaginar um futuro outro para si mesma. E sua consideração final, que reconhece momentos de aprisionamento em todas as existências, dentro e fora do cárcere, revela um ponto de vista ampliado sobre as contradições e vicissitudes que, em última instância, constituem a complexidade da experiência humana.

No espaço carcerário, onde papel e caneta são objetos escassos e, portanto, muito valorizados, a palavra falada e escrita a partir de momentos de leitura íntima ou compartilhada permite às leitoras-autoras a ressignificação de diferentes dimensões de suas existências. A possibilidade de elaboração dessas palavras assegura a essas mulheres - e, como sabemos, aos seres humanos de maneira mais geral - a sobrevivência de uma necessidade profunda: a de (se) narrar. 


\section{0 que pode a literatura?}

As experiências de mediação de leitura e de acompanhamento dos processos de escrita das resenhas literárias que se deram no âmbito do projeto Travessia fazem pensar na relação entre ler, escrever e resistir. Entre narrativa e resistência.

Ao longo de dois anos, o grupo de mediadores precisou constantemente pensar e repensar estratégias de atuação. Num jogo contínuo de geração e de quebra de expectativas, os ideais tão bem construídos e cultivados dentro da universidade foram sistematicamente colocados em xeque. Nesse sentido, o alinhamento ideológico e o repertório teórico, as boas intenções e a boa vontade do grupo pareceram estar sempre aquém das experiências vividas. De qualquer forma, a convicção de que a literatura é um direito essencial de todas as pessoas ganhou, nos contornos do projeto, o vigor da prática; nesse sentido, gerou as evidências necessárias para se criar novas possibilidades no âmbito da formulação de políticas públicas para a remição de pena por leitura e contribuir com a reflexão metodológica sobre a formação de leitores, considerando a potencialidade da leitura literária no ambiente prisional.

Não há humanidade possível sem o convívio com o universo ficcional nas suas mais variadas esferas: da canção popular às produções escritas que exigem maior fôlego. Atravessando as diversas narrativas 
que circulam diariamente intramuros e as escritas produzidas dentro do cárcere, a leitura da literatura no cotidiano das leitoras da Penitenciária Feminina da Capital representou um ato de resistência frente a desumanização promovida pelo sistema carcerário e frente as tramas de desigualdades sociais, raciais e de gênero responsáveis pelo encarceramento de mulheres do Brasil.

\section{Referências}

ABREU, Márcia. Cultura letrada. Literatura e cultura. São Paulo: Editora UNESP, 2006.

AMADO, Jorge. Capitães da areia. São Paulo: Companhia das Letras, 2009.

BAJOUR, Cecilia. Ouvir nas entrelinhas: o valor da escuta nas práticas de leitura. São Paulo: Pulo do gato, 2012. BORGES, Juliana. Encarceramento em massa. São Paulo: Pólen, 2019.

BOSI, Alfredo. "Narrativa e resistência". In: BOSI, Alfredo. Literatura e resistência. São Paulo: Companhia das Letras, 2002.

CANDIDO, Antonio. "O direito à literatura". In: CANDIDO, Antonio. Vários escritos. São Paulo: Duas Cidades, 1995.

DAVIS, Angela. Estarão as prisões obsoletas? Rio de Janeiro: Bertrand Brasil, 2018.

DEPEN - Departamento Penitenciário Nacional. Levantamento Nacional de Informações Penitenciárias: InfoPen (Julho 2019). Ministério da Justiça, 2019.

HOOKS, Bell. Ensinando a transgredir: a educação como prática da liberdade. São Paulo: Martins Fontes, 2017.

FRANK, Anne. 0 diário de Anne Frank. Rio de Janeiro: Record, 1995. 
PETIT, Michèle. A arte de ler ou como resistir à adversidade. São Paulo: Editora 34, 2009.

PETIT, Michèle. Leituras: do espaço íntimo ao espaço público. São Paulo: Editora 34, 2013.

PETIT, Michèle. Ler o mundo. Experiências de transmissão cultural nos dias de hoje. São Paulo, Editora 34, 2019. WPB - World Prison Brief. Highest to Lowest - Prison Population Total. London: WPB, 2020a. Disponível em: https:// www.prisonstudies.org/highest-to-lowest/prison-population-total?field region taxonomy tid=All. Acesso em: 21 dez. 2020. 